\title{
DOME STRUCTURE IN CONGLOMERATE ${ }^{\mathrm{x}}$
}

\section{RALPH ARNOLD}

\section{CONTENTS}

Location and Composition of the Domes.

Eagle Rock.

Other Examples.

Summary of Observations.

Previous Theories Regarding the Origin of Domes.

Conclusions Regarding the Origin of Conglomerate Domes.

LOCATION AND COMPOSITION OF THE DOMES

On the flanks of Eagle Rock Valley, two miles west of Pasadena, Cal., are several dome-shaped structures developed in conglomerate. They resemble in a general way the granite domes of the Sierra Nevada, but are much smaller and also less isolated as regards the surrounding topography. The conglomerate is of lower Miocene age, is quite regularly bedded, somewhat tilted, and consists of sand pebbles and boulders of the granite, diorite, gabbro, gneiss, and other crystalline rocks which form the San Gabriel Mountains to the north. Some of the boulders are as much as 6 feet in diameter, although the average are not over 3 or 4 inches; some of the layers are little more than coarse pebbly sandstone.

\section{EAGLE ROCK}

The largest and most perfect example of a dome is found at the east end of the valley, and is called Eagle Rock. Fig. I is a view of Eagle Rock as seen from the southwest, and shows its position with respect to the surrounding topography. The "eagle" may also be seen on its 8o-foot precipitous west face. The hills west and south of the rock are of conglomerate, similar to, except softer than, that composing the dome, and dipping in the same direction. The hills immediately to the north-to the left of it in this view-are of crys-

I Read before the Geological Society of America, December 28, 1906, and published by permission of the Director, U. S. Geological Survey. 
talline rocks, and are separated from the conglomerate by a fault, the latter, however, having no apparent relation to the origin of the dome. The bedding of the conglomerate is plainly marked by the lines of protruding pebbles and cobbles on the south side of the rock.

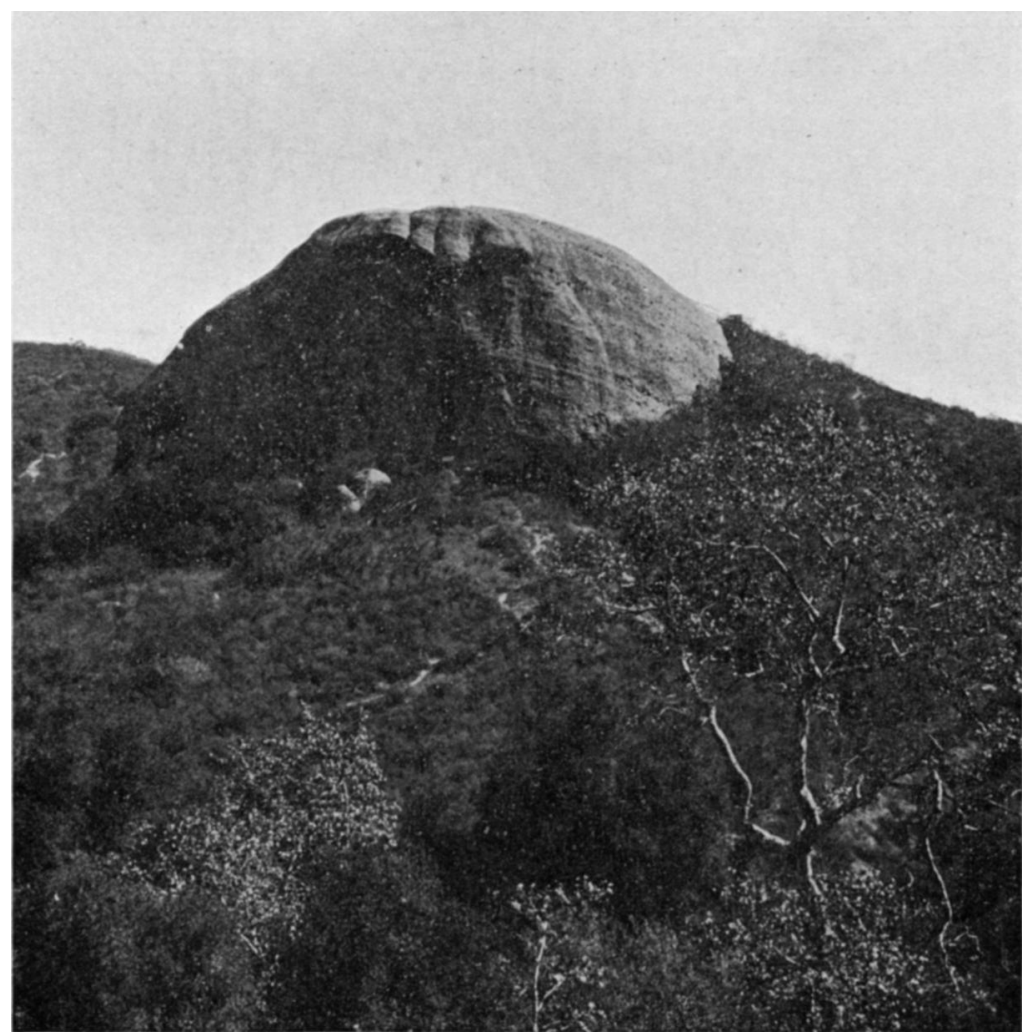

FIG. I.-View of Eagle Rock, a conglomerate dome, seen from the west, showing its relation to the surrounding topography: front elevation 80 feet.

The blocks immediately in front are fragments of the layer or shell, the remaining parts of which form the prominent overhanging V-shaped block. This layer was from six to eight feet through, and possibly more. A crack extends upward under the north arch of the overhanging block but none is present under the south arch, the block and adjacent dome face meeting in a solid concave junction. The 
iron stains seen on the west face of the rock in this view, and in Fig. 3, emanate from the cracks under the scales.

A view of Eagle Rock from the south is shown in Fig. 2. This picture presents a profile of its west face, showing the solid joint between overhanging block and nearly perpendicular rock face; also the rough, pebble-covered south wall of the dome. The top of the rock conforms approximately to the dip of the conglomerate, and

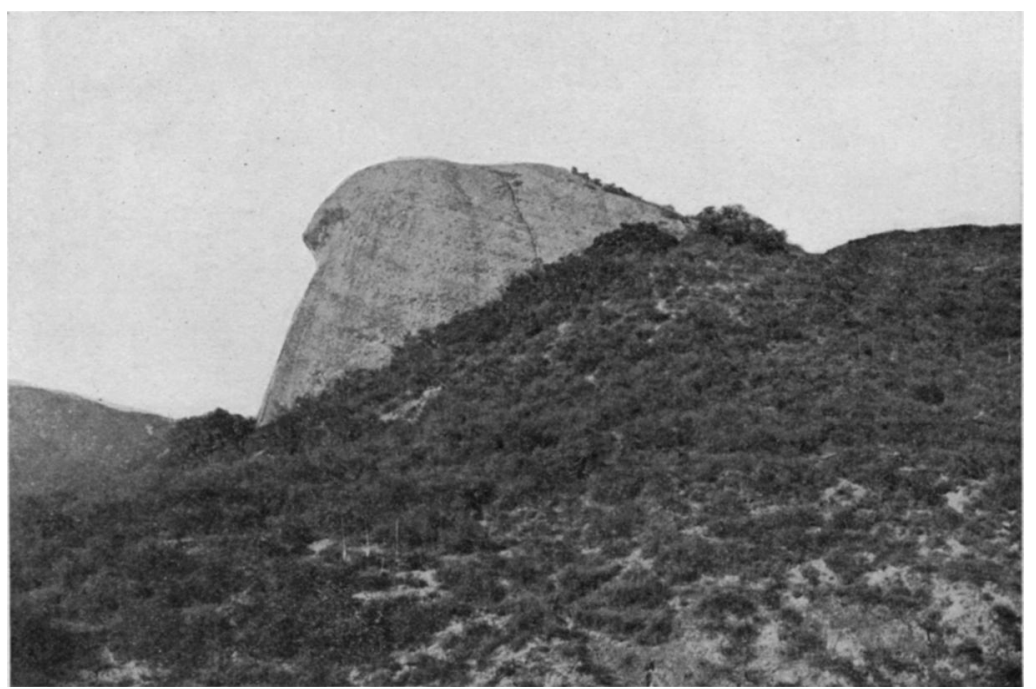

FIG. 2.-Eagle Rock, viewed from the south, showing bedding in the conglomerate, and a profile of the west face.

is devoid of vegetation with the exception of a patch or two of moss and a few straggling shrubs.

The north side of the dome, shown in Fig. 3, is penetrated by two caves which have been formed by the weathering-out of the incoherent portions of the rock. These caves are the result of phenomena different from those resulting in the scales and dome surfaces. The walls of the caves are concave inward, somewhat softer than the exposed surfaces of the dome; the bottoms of the caves slope gently outward. Beneath the caves will be noticed several arches similar in a general way to the great arch. These are of various sizes as 
regards length and thickness, and represent the lower edges of more or less well-developed scales. Small scales transverse to the larger ones are often developed across the lower portions of the latter, the line of parting always beginning at the interior surface of the larger scale and extending up into it toward its outer surface. An example of such a secondary scale is shown in Fig. 4, which is a profile of the north face of Eagle Rock. Many other scales, some of them from

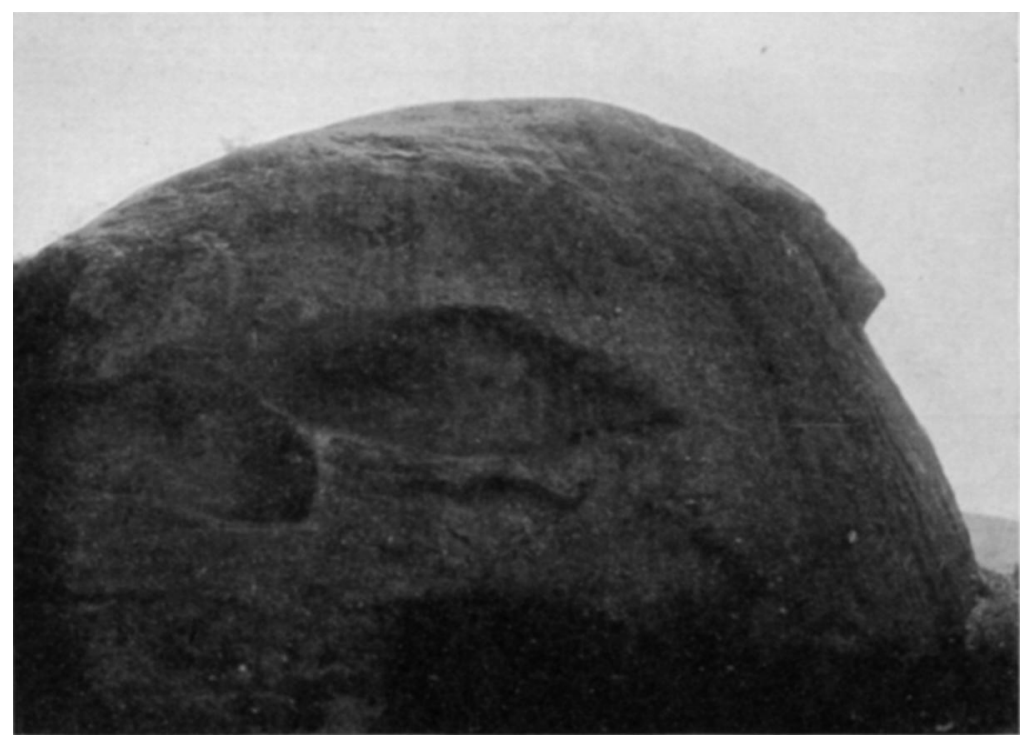

FIG. 3.-Near view of Eagle Rock, from the north, showing caves, some smaller arches, and profile of the west face.

one to six inches thick, and some thinner, but most of them inconspicuous in the photograph, are developed over the steeply sloping faces of the rock. It is a very significant fact that the interior walls of the caves, which are practically dry at all times, are not scaling off; neither is the south face, nor the top of the dome.

\section{OTHER EXAMPLES}

At the western end of the Eagle Rock Valley are several prominent examples of dome structure in conglomerate similar to that composing 
Eagle Rock. Some of these are little more than huge boulders, and one of them is only about ten feet in diameter. This last one, however, presents a very characteristic dome surface, with accompanying scales and arches on three sides, east, north, and west. In the vicinity of the small dome is the conglomerate exposure shown in Fig. 5.

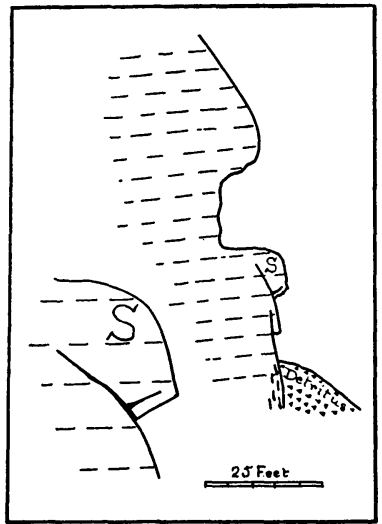

Fig. 4.-Profile of north face of Eagle Rock, with detail of scale at $\mathrm{S}$, latter showing transverse crack in scale. Taken as a whole it is but a small fraction of a complete dome, but it offers the best opportunity for detailed study of the phenomena of dome formation of any of the examples in this region. The view is looking north; the conglomerate dipping northeast. The surface bows over from a slope of $30^{\circ}$ to one of approximately $60^{\circ}$. The overhanging block on the face of the dome is about four feet thick at its thickest point, and consists of hard, littleweathered conglomerate. The block thins toward the southeast (the right in the photograph), the crack under it narrowing proportionately at the same time.

In direct contrast to this hard sheet is a 3 -foot zone of weathered rock shown in detail in Fig. 6, which was taken looking west into the crack extending under the outer shell on the left in Fig. 5. The hammer stands vertical, the handle resting on the hard surface of the new dome face, the head resting against the weathered zone, and the upper portion of the picture displaying the hard outer shell. The weathering process has resulted in the formation of a series of laminae (noticeable in the picture above the head of the hammer), from a small fraction of an inch to an inch in thickness extending approximately parallel to the dome surface. The planes separating the laminae pass through the conglomerate in most cases irrespective of the composition and hardness of the component parts of the rock, appearing to cut the hard granitic cobbles as readily as the softer arkose matrix. An exception to this is the exceedingly hard aplite boulder seen on the extreme left of the photograph. An idealized profile of the dome-face just described is shown in Fig. 7 . 
It is worthy of note that domes are so far known to occur only in plutonic rocks or in a clastic rock made up entirely of material of plutonic origin. This is true probably because the coincidence of texture and mineral constitution, essential to the peculiar type of weathering causing the scaling process, is confined to plutonic rocks.

\section{SUMMARY OF OBSERVATIONS}

Concerning the scaling process itself in the conglomerate the fol-

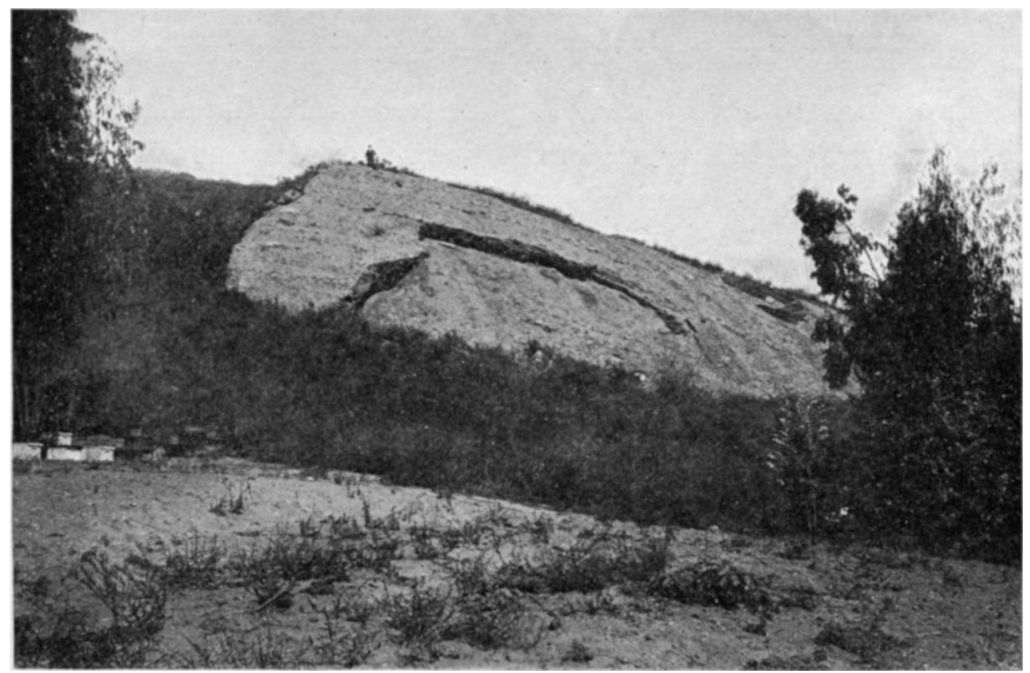

FIG. 5.-Dome surface in conglomerate at western end of Eagle Rock Valley, viewed from the south, showing crevice under large scale.

lowing observed facts and the deductions drawn from some of them may be given:

I. The scales are not found on slopes of less than $30^{\circ}$ or $40^{\circ}$, thus showing that the process is influenced by gravity.

2. The scales are almost entirely absent from the exposed southern faces and other portions of the rock, which are kept dry or practically dry, most of the time, indicating that moisture is a necessary agent in the process. The paucity of the scales on the surfaces most exposed to the sun argues against change in temperature being responsible for their formation. 
3. The cracks separating the scales from the dome-face always penetrate upward, never downward, and approximately parallel the outer surf ce of the scale.

4. The incipient cracks are closely followed by a zone of weathering which often shows thin lamination parallel to the crack, and which, crumbling away, produces a crevice. The intensity of the weathering which goes on in this zone is often evidenced by the iron and other stains which emanate from the cracks and run down the surface of the dome.

PREVIOUS THEORIES REGARDING THE ORIGIN OF DOMES

Two general theories have been advanced in explanation of such peculiar structure, all heretofore, however, based upon observations of the development of domes in granite. Gilbert ${ }^{\mathbf{I}}$ states these theories thus:

"According to one theory the separation of the granite into curved plates is an original structure, antedating the sculpture of the country and determining the peculiarities of form. According to the other theory the structure originated subsequently to the form, and was caused by some reaction from the surface."

Becker, ${ }^{2}$ Branner, ${ }^{3}$ Dana, ${ }^{4}$ Geikie, ${ }^{5}$ G. P. Merrill, ${ }^{6}$ Shaler, ${ }^{7}$ Turner, ${ }^{8}$ Gilbert, ${ }^{9}$ and Chamberlin and Salisbury ${ }^{10}$ support the latter theory, while Le Conte, ${ }^{11}$ Muir, ${ }^{12}$ Whitney, ${ }^{13}$ Bonney, ${ }^{14}$ and some German writers ${ }^{15}$ are in favor of the first.

I Bull. Geol. Soc. Am., Vol. XV, 1904, pp. 29, 30.

$2 U$. S. Geological Survey, Monograph I3, pp. 70-72, I888; Tenth Ann. Rept. U. S. Geol. Surv., I89o, p. I42; Bull. Geol. Soc. Am., Vol. II, I891, p. 69.

3 Bull. Geol. Soc. Am., Vol. VII, I896, p. 28I.

4 Manual of Geology, 1895, p. I27.

5 Textbook of Geology, 1893, p. 348.

${ }^{6}$ Rocks, Rock-Weathering and Soils, 1897, pp. 180-184.

7 Proc. Bost. Soc. Nat. Hist., Vol. XII, p. 289.

8 Proc. Cal. Acad. Sci., 3rd ser., Geology, Vol. I, p. 3 I5.

9 Loc. cit., pp. 30-34.

ro "Processes and Their Results," Geology, Vol. I, 1904, pp. 41-46.

II Elements of Geology, 4th ed., pp. 283, 284.

12 Proc.'A m. Assn. Adv. Sci., Vol. XXIII, pp. 6I, 62.

13 “Geol. Surv. Calif.," Geology, Vol. I, pp. 371, 372.

${ }^{1} 4$ Quart. Jour. Geol. Soc. London, Vol. XXXII, I876, p. I 49

15 Turner, H. W., loc. cit., p. $3^{1} 3$. 


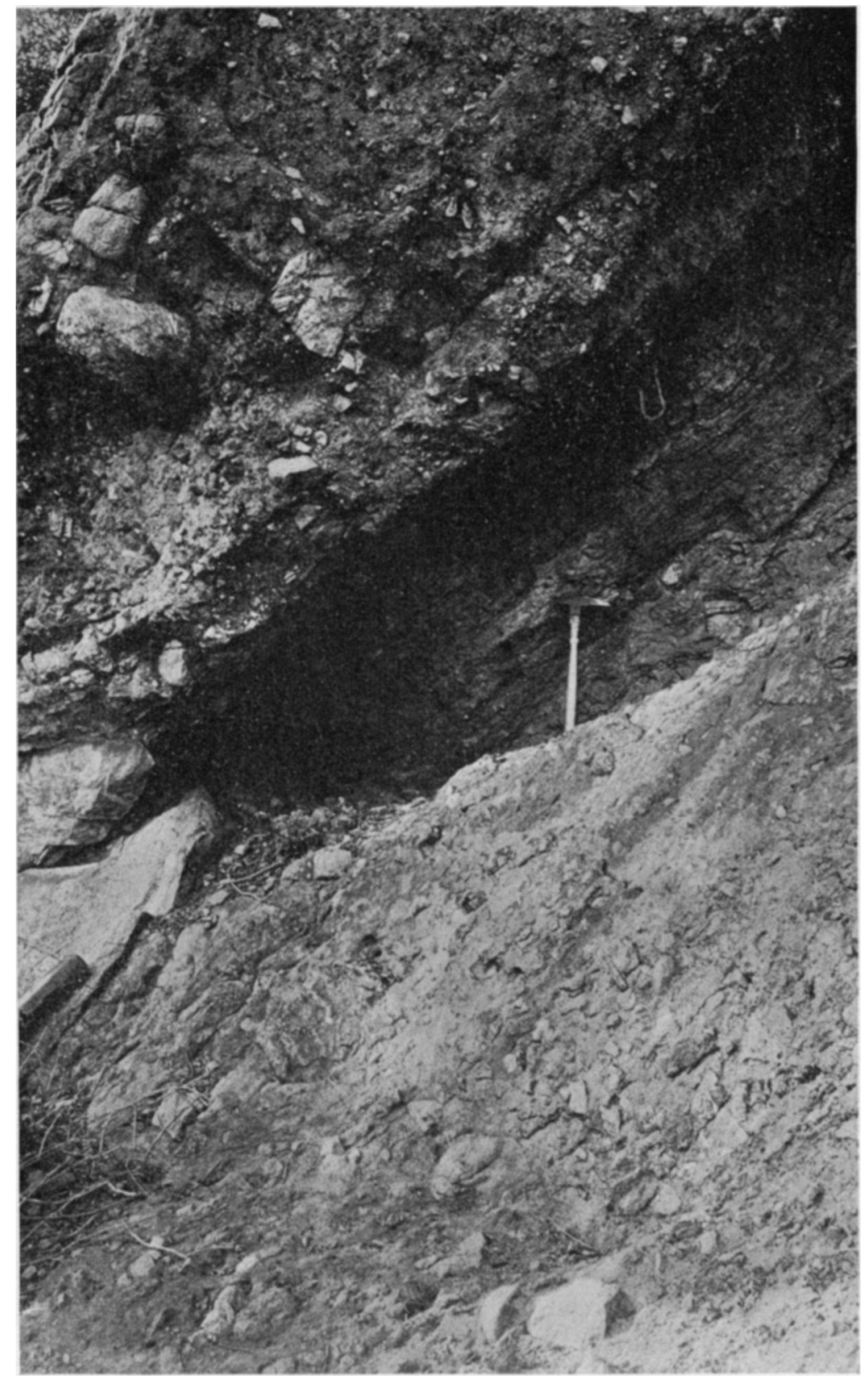

FIG. 6.-Detailed view of crevice shown in Fig. 5, looking west, showing lamination of the conglomerate in the weathered zone.

This content downloaded from 154.059.124.102 on October 17, 2016 16:27:27 PM All use subject to University of Chicago Press Terms and Conditions (http://www.journals.uchicago.edu/t-and-c). 
Those who support the theory of reaction from the surface differ as to the agent or agents which have brought about the result. Becker ${ }^{\mathrm{r}}$ believes the great granitic domes to be simply cases of exfoliation on a large scale, their regular curvature being due to the fact that, measured per unit volume, the surface exposed is in inverse ratio to the radius of curvature, so that the sharply curved surface weathers fastest. Furthermore

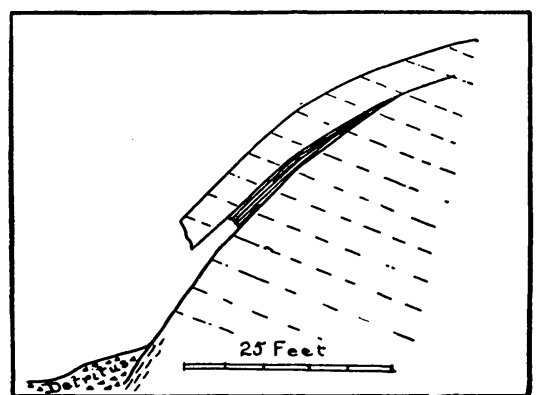

Fig. 7.-Section of dome at west end of Eagle Rock Valley, showing weathered zone below overhanging block. he says:" "Weathering and abrasion proceed with a rapidity which increases with the surface exposed per unit volume. Hence these processes lead to minimum surfaces. Therefore, also, the mathematics of erosion is essentially identical with that of capillarity."

Branner, ${ }^{3}$ from observations in Brazil, expresses the opinion that the even annual and diurnal changes and the approximately even penetrations of these changes cause the rocks to exfoliate or to shell off in layers of even thickness like the coat of an onion. Merrill ${ }^{4}$ attributes exfoliation largely to temperature changes, but considers the curved partings in the rock below the exfoliating surface as the result of torsional strains. Chamberlin and Salisbury ${ }^{5}$ account for exfoliation on both a small and a large scale (including the dome structures of the Sierra Nevada) by great daily, rather than by great annual, changes in temperature causing expansion and contraction in the outer layers of the rock. They also consider the wedge work of ice effective in augmenting the scaling caused by expansion. This latter cause would necessarily be inoperative in that part of southern California in which Eagle Rock is located, for the temperature here seldom descends to $32^{\circ} \mathrm{F}$.

I Tenth Ann. Rept. U. S. Geol. Surv., I89o, p. 142.

2 "Present Problems of Geophysics," Science, n. ser., Vol. XX, 1904, pp. 551, $55^{2}$.

3 Loc. cit., p. 28r.

4 Loc. cit., pp. $180-84$.

5 Loc. cit., pp. 42-44. 
Gilbert $^{\mathrm{I}}$ suggests three processes, all of which, according to him, may be concerned in the formation of domes, viz.: $(a)$ secular changes in temperature (he dismisses annual and diurnal changes because their influence penetrates but a small distance); $(b)$ expansive force developed in weathering, and (c) dilation from unloading.

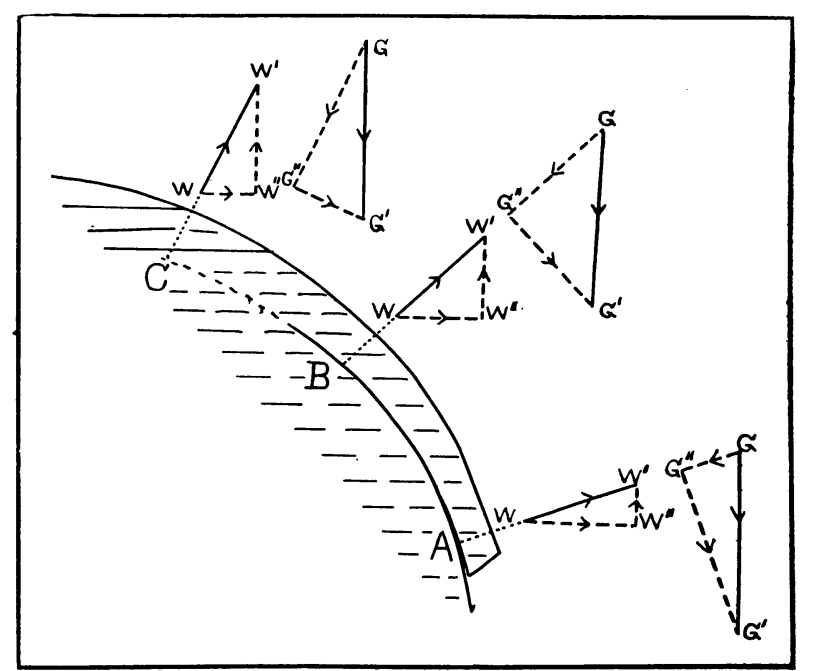

FIG. 8.-Graphic representation of some of the forces effective in dome formation. $\mathrm{WW}^{\prime}=$ expansive force due to weathering, acting at $\mathrm{A}, \mathrm{B}$, and $\mathrm{C}$.

$\mathrm{GG}^{\prime}=$ weight of overhanging or loosened block effective at $\mathrm{A}, \mathrm{B}$, and $\mathrm{C}$.

$\mathrm{WW}^{\prime}-\left(\mathrm{GG}^{\prime \prime}+\right.$ cohesion and adhesion of conglomerate $)=\mathrm{EF}=$ effective force tending to formation of crack.

The component of EF acting in the direction WW", and $\mathrm{G}^{\prime \prime} \mathrm{G}^{\prime}$ tend to removal of loosened block; these two forces become less and less as the slope of the dome surface decreases, reaching the value zero at the point where the tangent to the surface is horizontal; where the tangent is vertical they have their maximum value of $\mathrm{WW}^{\prime}$ and $\mathrm{GG}^{\prime}$, respectively. The scaling process is, therefore, most effective on vertical faces, becoming less and less so as the faces approach the horizontal.

CONCLUSIONS REGARDING THE ORIGIN OF CONGLOMERATE DOMES

The conclusions reached by the writer, regarding the origin of the conglomerate domes just described, involve both of the two general theories previously given, and may be tentatively stated as follows:

In the first place they are locally hardened portions (gigantic concretions, if you please) of a practically homogeneous conglome-

I Loc. cit., p. $3^{2}$. 
rate of plutonic rock material. After the ordinary process of erosion uncovers a sufficient surface of the indurated rock the dome structures are formed by a successive scaling-off of blocks, through the development of cracks approximately parallel to the steeply sloping surfaces. These cracks are probably due to expansive force developed by chemical reactions (weathering) produced largely by moisture, the moisture passing upward by capillarity through the incipient cracks caused by expansion, and thus advancing the process. The cracks originate in positions advantageous to the accumulation or retention of the moisture producing the weathering, such, for instance as that occupied by the detrital material at the base of the slope or in the angle between overhanging blocks and the new dome surface. The direction of the cracks is determined by the configuration of the rock surface, being approximately parallel to it, the departures from strict parallelism being of such a nature as to omit angles and other features of irregularity. This parallelism to the surface is due to the expansive force acting along lines of least resistance, which in this case are practically normal to the outer rock surface. The slope of the surface is the governing function in the removal of the scales because the components of gravity and of the expansive force tending to dislodge the separated scales is greater on steep slopes than on low, while the component of gravity tending to counteract the expansion due to weathering is correspondingly less on steep slopes, becoming greater as the angle of declivity lessens.

Fig. 8 illustrates graphically the two principal forces (expansive force due to weathering, and gravity) effective in dome formation. These forces are resolved into components at three different points on the dome surface, in order to make clear the last sentence in the preceding paragraph. 